\title{
Comparison of promoter-specific events during transcription initiation in mycobacteria
}

Correspondence

Valakunja Nagaraja

vraj@mcbl.iisc.ernet.in

Received 29 January 2010

Revised 13 March 2010

Accepted 17 March 2010

\author{
Arnab China, ${ }^{1}$ Priyanka Tare ${ }^{1}$ and Valakunja Nagaraja ${ }^{1,2}$ \\ ${ }^{1}$ Department of Microbiology and Cell Biology, Indian Institute of Science, Bangalore - 560012, \\ India \\ ${ }^{2}$ Jawaharlal Nehru Centre for Advanced Scientific Research, Bangalore - 560064, India
}

\begin{abstract}
DNA-protein interactions that occur during transcription initiation play an important role in regulating gene expression. To initiate transcription, RNA polymerase (RNAP) binds to promoters in a sequence-specific fashion. This is followed by a series of steps governed by the equilibrium binding and kinetic rate constants, which in turn determine the overall efficiency of the transcription process. We present here the first detailed kinetic analysis of promoter-RNAP interactions during transcription initiation in the $\sigma^{\mathrm{A}}$-dependent promoters $\mathrm{P}_{r r n A P C L 1}, \mathrm{P}_{r r n B}$ and $\mathrm{P}_{g y r}$ of Mycobacterium smegmatis. The promoters show comparable equilibrium binding affinity but differ significantly in open complex formation, kinetics of isomerization and promoter clearance. Furthermore, the two $r r n$ promoters exhibit varied kinetic properties during transcription initiation and appear to be subjected to different modes of regulation. In addition to distinct kinetic patterns, each one of the housekeeping promoters studied has its own rate-limiting step in the initiation pathway, indicating the differences in their regulation.
\end{abstract}

\section{INTRODUCTION}

Transcriptional regulation is one of the major mechanisms controlling gene expression in prokaryotes. RNA polymerase (RNAP), the central enzyme involved in bacterial transcription, consists of $\beta, \beta^{\prime}, \omega$ and two $\alpha$ subunits along with one of several sigma factors. The transcription process is divided into three phases: initiation, elongation and termination (Helmann, 2009). The initiation event itself can be subdivided into multiple steps, including a series of sequence-specific DNA-protein interactions between RNAP and the promoter. Transcription initiation is the most frequent target for regulation by different transcription factors and small molecule regulators. The pathway has been most extensively studied for Escherichia coli RNAP (Browning \& Busby, 2004; Haugen et al., 2008).

Analysis of transcription and other essential molecular processes in mycobacteria has recently become important to better understand the biology of the organism due to the global re-emergence of tuberculosis and other mycobacterial infections. Genome sequencing and comparative sequence analysis have revealed the presence of 13 sigma factors in Mycobacterium tuberculosis and 26 in Mycobacterium smegmatis (Cole et al., 1998; Manganelli

Abbreviations: Ft, fraction of bound complex; $\mathrm{PC}_{90 \%}, 90 \%$ promoter clearance; RNAP, RNA polymerase; $\mathrm{RP}_{\mathrm{C}}$, closed complex; $\mathrm{RP}_{\mathrm{O}}$, open complex; STB, standard transcription buffer.

A supplementary method and seven supplementary figures are available with the online version of this paper. et al., 1999; Rodrigue et al., 2006; Waagmeester et al., 2005). The primary sigma factor, $\sigma^{\mathrm{A}}$, is responsible for transcribing housekeeping genes and it is homologous to the E. coli $\sigma^{70}$ class of sigma factors (Gomez et al., 1998). Although the RNAP, sigma factors and several transcription factors from $M$. smegmatis and $M$. tuberculosis have been characterized (Gomez \& Smith, 2000; Smith et al., 2005), kinetic mechanisms of the promoter-RNAP interactions during transcription initiation and their effect on gene regulation are yet to be understood. While these processes have been well studied in several systems (Haugen et al., 2008; Jia \& Patel, 1997; Juang \& Helmann, 1995), many aspects may differ significantly in mycobacteria due to the high GC content of the genome and the slow growth rate. Furthermore, the regulation of essential housekeeping functions may be different in mycobacteria. For example, factors such as Fis and DksA, which are well established regulators of rRNA transcription in E. coli, are absent in mycobacterial genomes (Brosch et al., 2001; Cole et al., 1998). To understand the different steps of promoter-polymerase interactions and to obtain the first glimpse of events during transcription initiation in $M$. smegmatis, three housekeeping promoters were chosen for the present study, viz. two $\mathrm{rrn}$ promoters (Gonzalez-y-Merchand et al., 1998) and the gyr operon promoter (Unniraman \& Nagaraja, 1999). In vitro promoter binding and transcription assays were carried out to analyse each step of transcription initiation, namely closed complex $\left(\mathrm{RP}_{\mathrm{C}}\right)$ 
formation, isomerization to open complex $\left(\mathrm{RP}_{\mathrm{O}}\right)$ and its stability, abortive transcription and promoter clearance. Our results show that the initiation and kinetics are characteristic of a given promoter in mycobacteria and that the strength of each of the promoters is governed at different steps of the initiation process.

\section{METHODS}

Bacterial strains, culture conditions and in vivo promoter activity. M. smegmatis $m c^{2} 155$ (used for in vivo $\beta$-galactosidase assays) and M. smegmatis SM07 (used for RNAP purification) were cultured in Middlebrook 7H9 medium (Difco) containing $0.05 \%$ Tween-80 (Sigma) and $0.4 \%$ glucose (Sigma) with shaking, at $37{ }^{\circ} \mathrm{C}$. To measure the in vivo activity of the promoters, the fragments were cloned into the mycobacterial low-copy-number promoterless reporter vector pSD5b (Jain et al., 1997). The fragments used for cloning were amplified by PCR using the primers listed in Table 1. The promoter sequences consist of $\mathrm{nt}-69$ to +120 for $\mathrm{P}_{\text {rrnAPCL1 }}$, -125 to +180 for $\mathrm{P}_{r r n B}$ and -47 to +109 for $\mathrm{P}_{g y r}$. Promoter strength was measured by using a $\beta$-galactosidase reporter assay and the activity is represented in Miller units \{Miller units $=1000 \times A_{420} /$ [time $(\mathrm{min}) \times$ culture volume $(\mathrm{ml}) \times \mathrm{OD}_{600}$ ] (Miller, 1992) $\}$. M. smegmatis $m c^{2} 155$ transformed with pSD5b was used as the negative control.

RNAP purification, EMSA and preparation of transcription templates. M. smegmatis RNAP with a C-terminal hexa-histidine tag in the $\beta^{\prime}$ subunit was purified after in vivo enrichment of $\sigma^{\mathrm{A}}$, as described previously (China \& Nagaraja, 2010). The $\sigma^{\mathrm{A}}$ content in the RNAP preparation used for the assays was $>95 \%$ stoichiometric to the $\beta \quad \beta^{\prime}$ subunits. The specific activity of the purified RNAP was determined by using two methods: (i) by transcription assays using the standard method of ${ }^{3}[\mathrm{H}]-\mathrm{UTP}$ incorporation and (ii) by EMSA using radiolabelled promoter DNA. The concentration of RNAP required for $50 \%$ binding to promoter DNA was used for the binding and kinetic assays. Synthetic oligonucleotides (Sigma) containing promoter sequences of $95\left(\mathrm{P}_{r r n A P C L 1}\right), 91\left(\mathrm{P}_{r r n B}\right)$ and $75\left(\mathrm{P}_{g y r}\right)$ nt were used in all the EMSAs. Oligonucleotides were 5 '-end labelled with $\gamma-{ }^{32} \mathrm{P}[\mathrm{ATP}]$ (Perkin Elmer) using T4 polynucleotide kinase (NEB) and annealed with $2 \mathrm{~mol}$ excess of complementary strand and used for EMSAs (Table 1). The RNAP-promoter complexes were analysed by using $4 \%$ native PAGE. The electrophoresis was carried out at $4{ }^{\circ} \mathrm{C}$ or at room temperature for $\mathrm{RP}_{\mathrm{C}}$ and $\mathrm{RP}_{\mathrm{O}}$ formation assays, respectively. The templates for in vitro transcription assays were prepared from the pUC18 promoter constructs by amplification using PCR, using a set of vector-specific primers followed by purification from the gel using a purification kit (Qiagen).

$\mathbf{R P}_{\mathbf{c}}$ and $\mathbf{R} \mathbf{P}_{\mathbf{o}}$ formation and stability assays. For $\mathrm{RP}_{\mathrm{C}}$ formation assays, $1 \mathrm{nM}$ labelled DNA and increasing concentrations of RNAP $(1.25-200 \mathrm{nM})$ were incubated on ice using standard transcription buffer (STB; $50 \mathrm{mM}$ Tris/HCl, $5 \mathrm{mM}$ magnesium acetate, $100 \mu \mathrm{M}$ DTT, $5 \%$ glycerol, $50 \mu \mathrm{g} \mathrm{BSA} \mathrm{ml}^{-1}$ and $50 \mathrm{mM} \mathrm{KCl}$ ) for $15 \mathrm{~min}$ and loaded onto a native PAGE gel. To form the competitor-resistant open complexes, RNAP and promoters were incubated at $37{ }^{\circ} \mathrm{C}$ for $15 \mathrm{~min}$ followed by the addition of $50 \mu \mathrm{g}$ heparin $\mathrm{ml}^{-1}$. The DNA-

Table 1. Oligonucleotides, strains and plasmids used in this study

\begin{tabular}{|c|c|c|}
\hline $\begin{array}{l}\text { Oligonucleotide/strain/ } \\
\text { plasmid }\end{array}$ & Description $^{*}$ & Reference \\
\hline M. smegmatis SM07 & $\mathrm{Hyg}^{\mathrm{R}}, r p o C$ is replaced with $r p o C$ with a hexa-histidine coding tag at the $3^{\prime}$ end & $\begin{array}{l}\text { Mukherjee \& } \\
\text { Chatterji (2008) }\end{array}$ \\
\hline M. smegmatis $m c^{2} 155$ & A high-efficiency transformation strain of $M$. smegmatis & Snapper et al. (1990) \\
\hline $\mathrm{P}_{g y r}$ For & CGGAGCTCCAGAATCGGTGCTGTC & This work \\
\hline $\mathrm{P}_{g y r} \mathrm{Rev}$ & GAATGAGCTCGGATCCGGCGCCATACTCC & This work \\
\hline $\mathrm{P}_{r r n A P C L 1}$ For & GCGAGCTCGAGAAAACAACCCGGT & This work \\
\hline $\mathrm{P}_{\text {rrnAPCL1 }} \mathrm{Rev}$ & CAAAAGAGCTCACCTCTAGACGGGAAAAAG & This work \\
\hline $\mathrm{P}_{r r n B}$ For & CTTCTAGAGAGCTCGCTGGTGTTGCGGCGTG & This work \\
\hline $\mathrm{P}_{r r n B} \mathrm{Rev}$ & CTGAGCTCGCATGCCCGACTTTGCCGCGCAAG & This work \\
\hline $\mathrm{P}_{g y r}$ Sense & $\begin{array}{l}\text { AATTGAAACGCGGCTACAGAATCGGTGCTGTCGCTATCTCGCGGTAGAC- } \\
\text { TGGACGACGGATCTCAGGCGGTGTCTG }\end{array}$ & This work \\
\hline $\mathrm{P}_{g y r}$ Anti-sense & $\begin{array}{l}\text { GATCCAGACACCGCCTGAGATCCGTCGTCCAGTCTACCGCGAGATAGCG- } \\
\text { ACAGCACCGATTCTGTAGCCGCGTTTG }\end{array}$ & This work \\
\hline $\mathrm{P}_{r r n A P C L 1}$ Sense & $\begin{array}{l}\text { AATTCCGCGGAGCGGAGAAAACAACCCGGTCCAAGCGACTTGACAAGCC- } \\
\text { AGACAAAGCAGTATTAAGCTGGCAGGGTTGCCCCAAAACGGGGCG }\end{array}$ & This work \\
\hline $\mathrm{P}_{\text {rrnAPCL1 }}$ Anti-sense & $\begin{array}{l}\text { GATCCGCCCCGTTTTGGGGCAACCCTGCCAGCTTAATACTGCTTTGTCTG- } \\
\text { GCTTGTCAAGTCGCTTGGACCGGGTTGTTTTCTCCGCTCCGCGG }\end{array}$ & This work \\
\hline $\mathrm{P}_{r r n B}$ Sense & $\begin{array}{l}\text { GTCTGACCAGGGAAAATAGCCCTCTGACCTGGGGATTTGACTCCCAGTTT- } \\
\text { CCAAGGACGTAACTTATTCCAGGTCAGAGCGACACGGCCCAG }\end{array}$ & This work \\
\hline $\mathrm{P}_{r r n B}$ Anti-sense & $\begin{array}{l}\text { CTGGGCCGTGTCGCTCTGACCTGGAATAAGTTACGTCCTTGGAAACTGGG- } \\
\text { AGTCAAATCCCCAGGTCAGAGGGCTATTTTCCCTGGTCAGAC }\end{array}$ & This work \\
\hline pJAM2 mys $A$ & M. smegmatis mysA gene encoding $\sigma^{\mathrm{A}}$ cloned in pJAM2 & $\begin{array}{l}\text { Triccas et al. (1998); } \\
\text { laboratory stock }\end{array}$ \\
\hline pSD5b & E. coli-mycobacteria shuttle vector with promoterless lac $Z$ & Jain et al. (1997) \\
\hline
\end{tabular}

${ }^{\star}$ Oligonucleotide sequences are given in $5^{\prime}-3^{\prime}$ orientation. 
protein complexes separated by PAGE from the free DNA were quantified using Multi Gauge software version 2.3 (Fujifilm). $K_{\mathrm{B}}$ values were determined by Prism software using the following equations, $\mathrm{D}+\mathrm{P} \rightleftharpoons \mathrm{DP}$ and $K_{\mathrm{B}}=[\mathrm{DP}] /[\mathrm{D}][\mathrm{P}]$, where [D] corresponds to the concentration of free DNA, $[\mathrm{P}]$ corresponds to that of RNAP and $[\mathrm{DP}]$ that of the DNA-protein complex. The $[\mathrm{DP}] /[\mathrm{D}]$ values were plotted as a function of RNAP concentration, where the slope of the linear plot was equal to $K_{\mathrm{B}}$ of RNAP binding (Chakraborty \& Nagaraja, 2006). The $K_{\mathrm{B}}$ values were calculated from three independent sets of experiments and the mean was taken. The equilibrium dissociation constant for the heparin-resistant complex $\left(K_{\mathrm{d}}\right)$ was measured by the equation $Y=Y_{\max }[\mathrm{RNAP}] /\left(K_{\mathrm{d}}+[\mathrm{RNAP}]\right)$, where $Y_{\max }$ corresponds to binding maximum (Schroeder et al., 2007). The salt sensitivity of $\mathrm{RP}_{\mathrm{C}}$ was determined by carrying out the binding reactions in the presence of increasing concentrations of $\mathrm{KCl}$. The temperature dependency of $\mathrm{RP}_{\mathrm{O}}$ formation was determined by carrying out run-off transcription reactions using $25 \mathrm{nM}$ template and $100 \mathrm{nM}$ RNAP. The reactions were incubated at different temperatures $\left(0,7,15,22,30,37\right.$ and $\left.44{ }^{\circ} \mathrm{C}\right)$ prior to the addition of NTPs. Transcription was initiated by the addition of NTPs, $\alpha_{-}{ }^{32} \mathrm{P}[\mathrm{UTP}]$ and $50 \mu \mathrm{g}$ heparin $\mathrm{ml}^{-1}$ and the mixture was incubated further at $37^{\circ} \mathrm{C}$.

\section{Association and dissociation kinetics.}

$\mathbf{R P}_{\mathrm{O}}$ formation. RNAP (100 $\left.\mathrm{nM}\right)$ and labelled promoter DNA (1 nM) were mixed and incubated at $37^{\circ} \mathrm{C}$. Equal volumes were split into aliquots at different time points and challenged with heparin $(50 \mu \mathrm{g}$ $\mathrm{ml}^{-1}$ for $1 \mathrm{~min}$ ) before loading onto a $4 \%$ native PAGE gel which was run at room temperature (see Fig. 4a, upper path). The amount of RNAP-promoter complex obtained at various time points was normalized to that obtained after the longest incubation time to determine the fraction of bound complex $(\mathrm{Ft}) . \mathrm{k}^{\prime}$ (pseudo first-order rate constant) was measured by using the equations described previously (Brunner \& Bujard, 1987; Lutz et al., 2001). The Ft values were fitted into a single exponential equation to determine the rate constants (Supplementary Methods, available with the online version of this paper).

$\mathrm{RP}_{\mathrm{O}}$ decay. The rate of $\mathrm{RP}_{\mathrm{O}}$ decay was determined by incubating $100 \mathrm{nM}$ RNAP and $1 \mathrm{nM}$ promoter DNA at $37^{\circ} \mathrm{C}$ for $15 \mathrm{~min}$ followed by challenge with $50 \mu \mathrm{g}$ heparin $\mathrm{ml}^{-1}$. Aliquots were taken out at different times and loaded onto a $4 \%$ native PAGE gel (see Fig. $4 \mathrm{a}$, lower path). The level of radioactivity in the bound fraction was quantified and the fraction of bound complex was plotted as a function of time. $k_{\text {off }}$ and $t_{1 / 2}$ of the promoters were calculated using the equation, $\ln (\mathrm{Ft})=-k_{\text {off }} \times t$. The half-life of the decay was calculated as $0.6932 / \mathrm{k}_{\text {off }}$ (Brunner \& Bujard, 1987; Straney \& Crothers, 1987; Tsujikawa et al., 2002).

\section{In vitro transcription.}

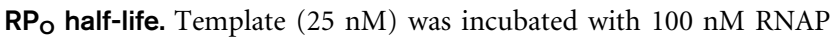
in STB at $37{ }^{\circ} \mathrm{C}$ for $15 \mathrm{~min}$ to form $\mathrm{RP}_{\mathrm{O}}$ in a reaction volume of $70 \mu$ l. Heparin $\left(50 \mu \mathrm{g} \mathrm{ml} \mathrm{m}^{-1}\right)$ was added and incubation was continued for another $1 \mathrm{~min}$. Aliquots were taken out at regular intervals and mixed with $100 \mu \mathrm{M}$ NTPs and $1 \mu \mathrm{Ci} \alpha-{ }^{32} \mathrm{P}[\mathrm{UTP}]$ to initiate the RNA chain elongation. The reactions were stopped with $2 \times$ gel loading buffer $[0.025 \%(\mathrm{w} / \mathrm{v})$ bromophenol blue, $0.025 \%(\mathrm{w} / \mathrm{v})$ xylene cyanol FF, $5 \mathrm{mM}$ EDTA, $0.025 \%$ SDS and $8 \mathrm{M}$ urea] and separated by using $8 \%$ urea PAGE.

Promoter clearance. After the open complexes were incubated with $50 \mu \mathrm{g}$ heparin $\mathrm{ml}^{-1}$ for $1 \mathrm{~min}$, transcription was initiated by the addition of $100 \mu \mathrm{M}$ NTPs and $1 \mu \mathrm{Ci} \alpha-{ }^{32} \mathrm{P}[\mathrm{UTP}]$. Aliquots were withdrawn at different time intervals and the reaction mixtures were incubated for 1, 2, 5 or 10 min (Fig. 5a; Chakraborty \& Nagaraja, 2006). The reactions were stopped and separated as above.
Abortive transcription. Single round transcription reactions were carried out as described above. Heparin was omitted from the reaction mix while the multiple round reactions were carried out. The transcripts were analysed by using $22 \%$ urea PAGE to resolve the abortive products (Hsu, 2009). Abortive transcripts resulting from different ratios of template $(10 \mathrm{nM})$ and RNAP ranging from $2: 1$ to $1: 20$ in a single round transcription assay were also analysed by using $22 \%$ urea PAGE.

RPo formation in the presence of initiating NTP and pppGpp. Assays were carried out by adding increasing concentrations of iGTP (initiating nucleotide for all three promoters) and detecting the amount of $\mathrm{RP}_{\mathrm{O}}$ formed by EMSA. To determine the fraction of closed complexes converted to the open complex, aliquots from the same assay mix incubated at $0{ }^{\circ} \mathrm{C}$ were moved to $37^{\circ} \mathrm{C}$ and were incubated for $15 \mathrm{~min}$. Two aliquots were taken out; one was treated with heparin and one was not. Both the samples were loaded onto a $4 \%$ native PAGE gel and run at $4{ }^{\circ} \mathrm{C}$. The assay was carried out in both the absence and the presence of $200 \mu \mathrm{M}$ GTP. The ability to form initiation complexes at all three promoters was tested by adding only the initial three NTPs to the reaction, ensuring the formation of only a ternary initiation complex (Schneider et al., 2003). The effect of pppGpp on $\mathrm{RP}_{\mathrm{O}}$ was determined by incubating the RNAP and promoter DNA in the presence of $100 \mu \mathrm{M}$ pppGpp at $37{ }^{\circ} \mathrm{C}$ for $15 \mathrm{~min}$. The complexes were analysed by EMSA after treating with $50 \mu \mathrm{g}$ heparin $\mathrm{ml}^{-1}$ for $1 \mathrm{~min}$.

\section{RESULTS}

\section{Promoter characteristics}

The $\sigma^{\mathrm{A}}$-dependent promoters from mycobacteria are architecturally similar to E. coli $\sigma^{70}$-dependent promoters (Gomez \& Smith, 2000; Unniraman et al., 2002). Three $\sigma^{\mathrm{A}}$ promoters involved in housekeeping functions were chosen for this study: $\mathrm{P}_{r r n A P C L 1}, \mathrm{P}_{r r n B}$ and $\mathrm{P}_{g y r}$ (Fig. 1a). Our earlier studies revealed that $\mathrm{P}_{g y r}$ is a strong promoter with comparable high activity to other strong promoters (Unniraman \& Nagaraja, 1999). The two rRNA promoters chosen have been well characterized previously (Arnvig et al., 2005; Gonzalez-y-Merchand et al., 1998). Alignment of these mycobacterial promoter sequences with the $\sigma^{\mathrm{A}}$ consensus sequence shows their similarity, and two of the promoters $\left(\mathrm{P}_{r r n B}\right.$ and $\left.\mathrm{P}_{g y r}\right)$ exhibit strong in vivo activity (Fig. 1b) in accordance with previous observations (Arnvig et al., 2005; Unniraman \& Nagaraja, 1999). The M. smegmatis genome contains two rrn operons, rrnA and $r r n B$. The rrnA operon has two promoters, $\mathrm{P}_{r r n A P 1}$ and $\mathrm{P}_{\text {rrnAPCL1 }}$, both of which are conserved across the genus (Stadthagen-Gomez et al., 2008). Of the two, $\mathrm{P}_{\text {rrnAPCL1 }}$ is the major promoter in different species of mycobacteria and hence was chosen for the study. In contrast with the $r r n A$ operon, a single promoter, $\mathrm{P}_{r r n B}$, is known to transcribe the $r r n B$ operon. $\mathrm{P}_{r r n B}$ is one of the strongest rrn promoters characterized in mycobacteria (Arnvig et al., 2005; Ji et al., 1994). gyrB and gyrA in M. smegmatis are organized as an operon driven by a single promoter $\mathrm{P}_{g y r}$ (Unniraman \& Nagaraja, 1999). This is a strong promoter in vivo and responds to regulation by the topological status of DNA by the process termed as relaxation-stimulated transcription (Unniraman \& Nagaraja, 1999). A compar- 
ison of the -10 region of all three promoters shows that $\mathrm{T}$ at the first position, $\mathrm{A}$ at the second position and $\mathrm{T}$ at the sixth position are identical to the mycobacterial consensus sequence for the $\sigma^{\mathrm{A}}$-dependent promoters (Unniraman et al., 2002). These three bases are most conserved amongst the $\sigma^{\mathrm{A}}$-dependent promoters of mycobacteria (Gomez \& Smith, 2000) as well as $\sigma^{70}$ promoters of E. coli (Lisser \& Margalit, 1993) and are shown to play an important role during promoter DNA melting (McClure, 1985). The -35 site of $\mathrm{P}_{r r n A P C L 1}$ and $\mathrm{P}_{r r n B}$ shows similarity with the consensus sequence, while $\mathrm{P}_{g y r}$ has only two of six residues similar, although it shows strong in vivo activity. The spacer length between the -10 and -35 element of $\mathrm{P}_{r r n A P C L 1}$ and $\mathrm{P}_{r r n B}$ is 18 and $17 \mathrm{nt}$, respectively, compared with the $16 \mathrm{nt}$ spacer present in all E. coli rrn promoters. Thus, the promoters selected have the following characteristics: (i) they transcribe housekeeping genes; (ii) the transcription start site is mapped, and -10 and -35 sequences are defined; and (iii) they show in vivo activity in exponentially growing cells. For a direct comparison, activities of the promoters were determined in vivo by transforming $M$. smegmatis with promoter-lacZ transcriptional fusion constructs (Fig. 1b). All the promoters were active at early exponential growth phase. In these assays, $\mathrm{P}_{r r n B}$ had the highest activity followed by $\mathrm{P}_{g y r}$ and $\mathrm{P}_{r r n A P C L 1}$. Although the promoter sequences closely match the consensus sequences, $\mathrm{P}_{r r n A P C L 1}$ and $\mathrm{P}_{r r n B}$ showed contrasting promoter strength in vivo in exponential growth phase. The expression patterns of the promoters were analysed at different growth phases (Supplementary Fig. S1, available with the online version of this paper). $\mathrm{P}_{r r n B}$ was downregulated with no significant changes compared with $\mathrm{P}_{r r n A P C L 1}$ and $\mathrm{P}_{g y r}$ in stationary phase. The difference in the activity of the three promoters could be due to the variations in their interactions with RNAP. Hence, the different steps of transcription initiation at these promoters were investigated.

\section{Promoter binding and melting}

The transcription initiation events begin with the sequencespecific binding of RNAP to the promoters (Brunner \& Bujard, 1987; Buc \& McClure, 1985; McClure, 1985), forming a closed complex $\left(\mathrm{RP}_{\mathrm{C}}\right)$; Fig. 2 shows the sequential reaction pathway. To determine the equilibrium binding constants, promoter DNA and different concentrations of RNAP were maintained on ice for $15 \mathrm{~min}$ and the complexes were resolved by native PAGE (Fig. 3a). The $K_{\mathrm{B}}$ value of the RNAP is comparable for all three promoters (Fig. $3 \mathrm{~b}$ and Table 2). Although $\mathrm{P}_{r r n B}$ was the strongest among the three promoters in vivo (Fig. 1b), its high strength was not evident at the $\mathrm{RP}_{\mathrm{C}}$ formation step. Mycobacterial RNAP forms a promoter-specific complex at $0{ }^{\circ} \mathrm{C}$ at all the promoters tested. The complex is stable and resistant to challenge by $\sim 100 \mathrm{mM} \mathrm{KCl}$ (Supplementary Fig. S2). The RNAP also binds non-specifically to the double-stranded DNA. The promoter-non-specific complex is sensitive to treatment with $100 \mathrm{mM} \mathrm{KCl}$ (data not shown). In the next step of the transcription initiation pathway, $\mathrm{RP}_{\mathrm{C}}$ is converted to $\mathrm{RP}_{\mathrm{O}}$. The equilibrium dissociation constant $\left(K_{\mathrm{d}}\right)$ was determined for the three promoters by measuring the extent of competitor-resistant complex formation with increasing RNAP concentrations (Fig. 3c). In contrast with $\mathrm{RP}_{\mathrm{C}}$ formation, only a fraction of DNA was bound by the RNAP to form $\mathrm{RP}_{\mathrm{O}}$, even at saturating concentrations of the enzyme, indicating that only a subset of initially bound RNAP could form a competitor-resistant complex. $\mathrm{RP}_{\mathrm{O}}$ formation was significantly different for each one of the promoters. $\mathrm{P}_{r r n A P C L 1}$ and $\mathrm{P}_{r r n B}$ had threefold differences between their $K_{\mathrm{d}}$ values and $\mathrm{P}_{g y r}$ was found to have a $K_{\mathrm{d}}$

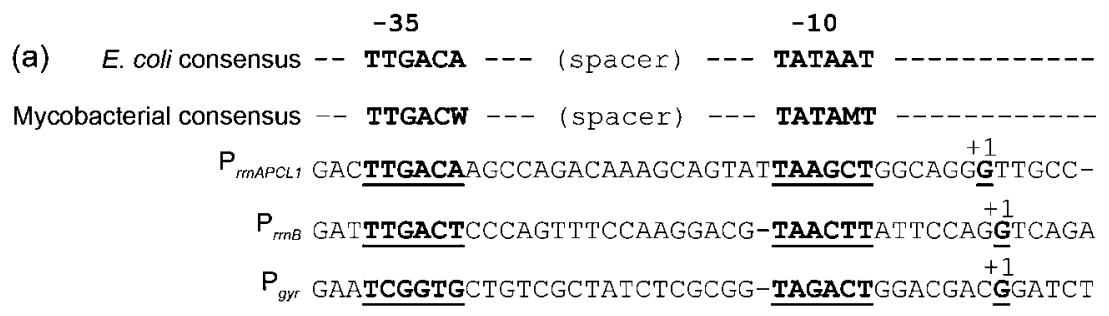

(b)

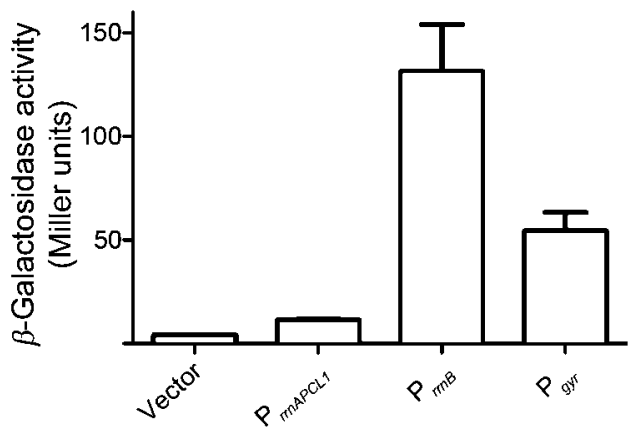

Fig. 1. Promoter structure and function. (a) Sequences of the three promoters aligned with the $E$. coli $\sigma^{70}$ - and mycobacterial $\sigma^{\mathrm{A}}$-dependent promoter consensus sequences. The $-35,-10$ and +1 (transcription start site) sites of each promoter are represented in bold. (b) In vivo activity of the promoters. $\beta$-Galactosidase reporter activity of the promoters cloned in pSD5b vector was measured from early exponential phase cultures of $M$. smegmatis. Error bars, SD. 


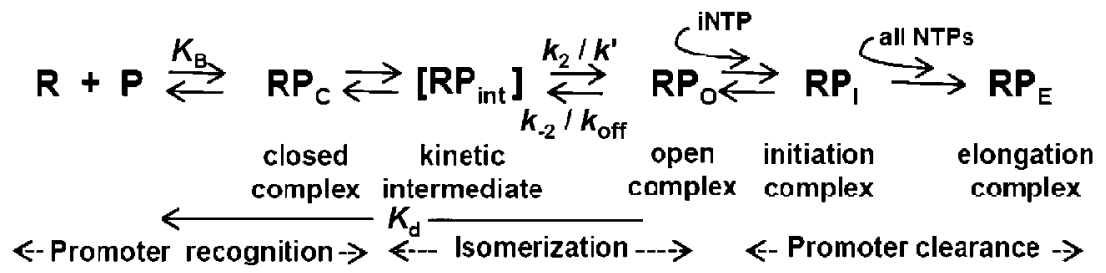

Fig. 2. Transcription initiation pathway. RNAP $(R)$ binds to the promoter $(P)$ through base-specific contacts mediated by the sigma factor to form a closed complex $\left(R P_{C}\right)$. In the subsequent step, $R_{C}$ undergoes conformational changes to form the competitor-resistant open complex ( $\mathrm{RP}_{\mathrm{O}}$ ), after melting of $12-14 \mathrm{bp}$ of the duplex DNA around the +1 site. The first two NTPs complementary to the +1 and +2 positions on the template strand bind to $\mathrm{RP}_{\mathrm{O}}$, forming the pre-initiation complex ready for elongation. At this stage, RNAP synthesizes short abortive transcripts of 2-14 nt before proceeding into the elongation mode. Promoter clearance, the last step of transcription initiation, involves RNAP switching from abortive synthesis to the productive elongation complex $\left(\mathrm{RP}_{\mathrm{E}}\right)$ (Haugen et al., 2008; Helmann \& deHaseth, 1999; McClure, 1985; Nudler, 2009). RP int transient intermediate complex; $\mathrm{RP}_{\mathrm{l}}$, ternary initiation complex.

value intermediate to these (Fig. $3 \mathrm{~d}$ and Table 2). Surprisingly, a higher dissociation of RNAP from the $\mathrm{P}_{r r n B}$ promoter is in contrast with its high in vivo promoter strength (see Fig. 1b).

Thermal energy is required for the duplex unwinding during the isomerization process to form $\mathrm{RP}_{\mathrm{O}}$. Different promoters may need a different degree of thermal energy for DNA melting. For example, most E. coli promoters studied so far are inactive at temperatures below $20{ }^{\circ} \mathrm{C}$ (Burns et al., 1996). In vitro transcription assays were carried out after incubating the promoter and RNAP at different temperatures ranging from $0-44{ }^{\circ} \mathrm{C}$ to determine the temperature at which the transition from closed to open complex occurs. Transcripts were not detected in reactions pre-incubated at temperatures less than $20{ }^{\circ} \mathrm{C}$. This is an indication that the complex formed below $20{ }^{\circ} \mathrm{C}$ is predominantly a closed complex (Supplementary Fig. S3).

\section{Kinetics of RPo formation and decay}

The rate of formation of competitor-resistant $\mathrm{RP}_{\mathrm{O}}$ is shown in Fig. 4(b). Interestingly, each of the promoters exhibited different kinetics for $\mathrm{RP}_{\mathrm{O}}$ formation. The rate constant for $\mathrm{RP}_{\mathrm{O}}$ formation was found to be $0.26 \pm 0.039 \mathrm{~min}^{-1}$ at the $\mathrm{P}_{r r n B}$ promoter, $0.098 \pm 0.016 \mathrm{~min}^{-1}$ at $\mathrm{P}_{\text {rrnAPCL1 }}$ and $0.11 \pm 0.024 \mathrm{~min}^{-1}$ at $\mathrm{P}_{\text {gyr }}$ (Fig. 4c), showing that these two rRNA promoters have threefold differences between them in the rate of isomerization. Although the $\mathrm{P}_{r r n B}$ promoter showed the highest rate of open complex formation amongst the three promoters, it exhibited a higher dissociation of the enzyme (Table 2), indicating that (a)

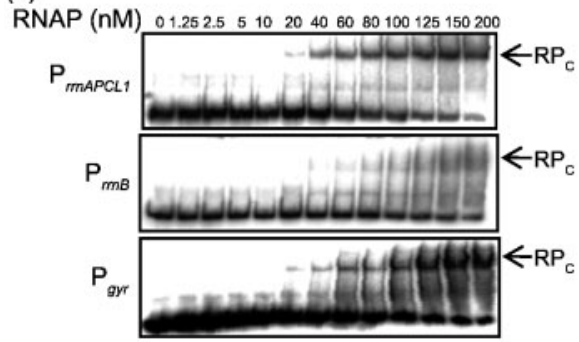

(c)

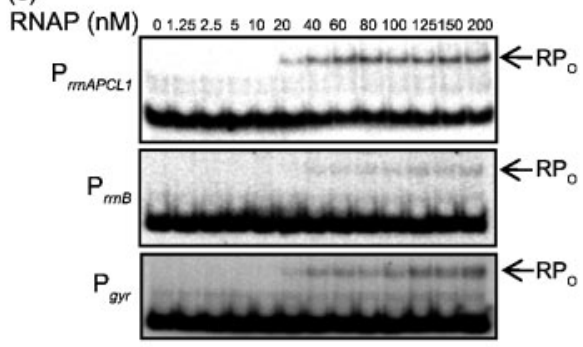

(b)

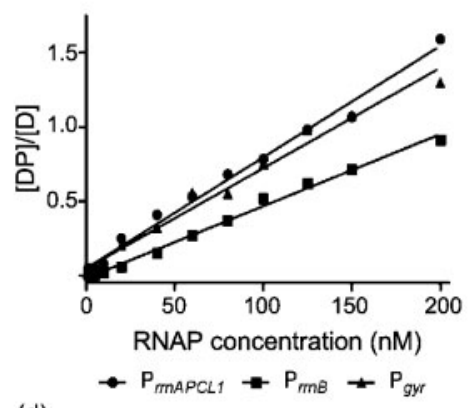

(d)

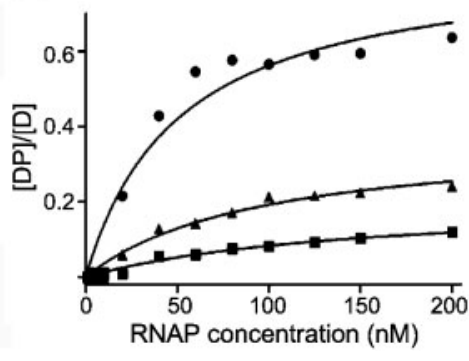

Fig. 3. $K_{\mathrm{B}}$ of RNAP binding and $K_{\mathrm{d}}$ of competitor-resistant complex. (a) Increasing concentrations of RNAP were incubated with the $5^{\prime}$-end labelled promoter fragments and resolved by using native PAGE. The smear in the gel resulted from the dissociation of complexes during electrophoresis. (b) The amount of free (D) and RNAP-bound (DP) DNA was quantified and analysed to determine the $K_{\mathrm{B}}$ of RNAP binding. [DP]/[D] values (bound:free DNA) are shown; the slopes of the plots are a measure of $K_{\mathrm{B}}$. (c) The $K_{\mathrm{d}}$ for the heparin-resistant complex was determined by incubating increasing concentrations of RNAP with the promoter fragments at $37^{\circ} \mathrm{C}$, followed by treatment with heparin and analysis using native PAGE run at room temperature. (d) The amount of RNAP-bound DNA (DP) was quantified and analysed to determine the $K_{\mathrm{d}}$ of the competitor-resistant complex. 
Table 2. Summary of equilibrium binding and kinetic rate constants

\begin{tabular}{|lccc|}
\hline Constant/property & $\mathbf{P}_{\text {rrnAPCL1 }}$ & $\mathbf{P}_{\boldsymbol{r r n B}}$ & $\mathbf{P}_{\mathbf{g y r}}$ \\
\hline $\begin{array}{l}\text { Relative in vivo } \\
\text { strength }\end{array}$ & 1 & 12 & 5 \\
$K_{\mathrm{B}}\left(\times 10^{6} \mathrm{M}^{-1}\right)^{*}$ & 7.5 & 4.9 & 6.8 \\
$K_{\mathrm{d}}\left(\times 10^{-7} \mathrm{M}^{-1}\right)^{*}$ & 0.51 & 1.47 & 0.95 \\
$k^{\prime}\left(\min ^{-1}\right)^{*}$ & $0.098 \pm 0.016$ & $0.26 \pm 0.039$ & $0.11 \pm 0.024$ \\
$k_{\text {off }}\left(\mathrm{min}^{-1}\right)^{*}$ & $0.105 \pm 0.015$ & $0.177 \pm 0.019$ & $0.046 \pm 0.009$ \\
$t_{1 / 2}(\min )^{*}$ & 6.5 & 3.9 & 14.9 \\
Abortive & ++++ & - & + \\
transcription $\dagger$ & & & \\
Promoter clearance, & 10 & 2.3 & 3.7 \\
PC $C_{90 \%}$ (min) & & & \\
\hline
\end{tabular}

${ }^{\star}$ Kinetic constants are shown in the transcription initiation equation presented in Fig. 2.

$\dagger$ Qualitative description of the level of abortive transcripts formed at each promoter.

the complex is very unstable. The $k_{\text {off }}$ of $\mathrm{RP}_{\mathrm{O}}$ was measured from the exponential decay (Fig. 4d). The rate of decay of $\mathrm{RP}_{\mathrm{O}}$ and its half-life $\left(t_{1 / 2}\right)$ were analysed for all three promoters. In spite of its higher isomerization rate, the $\mathrm{P}_{r r n B}$ promoter showed the highest $k_{\text {off }}(0.177 \pm 0.019$ compared with $0.105 \pm 0.015$ and $0.046 \pm 0.009$ for $\mathrm{P}_{r r n A P C L 1}$ and $\mathrm{P}_{g y n}$ respectively). The $t_{1 / 2}$ of the $\mathrm{P}_{r r n B}$ open complex was approximately $3.9 \mathrm{~min}$, followed by $\mathrm{P}_{r r n A P C L 1}(6.5 \mathrm{~min})$ and $\mathrm{P}_{g y r}(14.9 \mathrm{~min})$ (Table 2).

To further examine the above findings, in vitro single round transcription assays were carried out. These assays also enabled the extent of $\mathrm{RP}_{\mathrm{O}}$ stability to be determined. The run-off transcript length was $120 \mathrm{nt}$ for $\mathrm{P}_{r r n A P C L 1}, 180$ nt for $\mathrm{P}_{r r n B}$ and 109 nt for $\mathrm{P}_{g y r}$. The amount of run-off transcripts produced correlates with the fraction of transcriptionally active $\mathrm{RP}_{\mathrm{O}}$. The stability of $\mathrm{RP}_{\mathrm{O}}$ at $\mathrm{P}_{r r n B}$ was found to be lowest, followed by $\mathrm{P}_{r r n A P C L 1}$ and $\mathrm{P}_{g y r}$ (Fig. 4f). The values obtained in this set of assays are different from the earlier EMSA results, as the reaction conditions varied and included NTPs. However, the trend is similar irrespective of the assays used (Fig. 4e and f).

\section{Promoter clearance}

The last step in transcription initiation is promoter clearance. $\mathrm{RP}_{\mathrm{O}}$ is converted to a pre-initiation complex in the presence of initiating NTPs before proceeding to the elongation step after the synthesis of abortive transcripts. Promoter clearance assays were carried out to analyse the kinetics of polymerase escape into elongation (Fig. 5b). In these assays, the fastest kinetics of promoter escape were observed from the $\mathrm{P}_{r r n B}$ promoter. Once $\mathrm{RP}_{\mathrm{O}}$ was formed, transition into elongation was most rapid at this promoter $[90 \%$ promoter clearance $\left.\left(\mathrm{PC}_{90 \%}\right)=2.3 \mathrm{~min}\right]$. The promoter clearance at $\mathrm{P}_{r r n A P C L 1}$
$\left(\mathrm{PC}_{90 \%}=10 \mathrm{~min}\right)$ was more than fourfold slower than at $\mathrm{P}_{r r n B}$, while $\mathrm{P}_{g y r}\left(\mathrm{PC}_{90 \%}=3.7 \mathrm{~min}\right)$ showed relatively fast promoter escape. The slower promoter clearance at $\mathrm{P}_{\text {rrnAPCL1 }}$ appears to be its major rate-limiting step. To better understand these results and to further assess the late events during transcription initiation, abortive initiation assays were carried out. The results presented in Fig. 5(c) and Supplementary Fig. S4 reveal that the abortive transcription products were synthesized substantially at $\mathrm{P}_{r r n A P C L 1}$ and were lower and not readily detectable at $\mathrm{P}_{r r n B}$ and $\mathrm{P}_{g y r}$. The lower level of transcription seen at $\mathrm{P}_{r r n A P C L 1}$ is thus due to the high level of abortive transcription. The multiple round transcription reactions (Fig. 5d) show that the overall transcriptions at $\mathrm{P}_{r r n B}$ and $\mathrm{P}_{g y r}$ promoters were higher than at the $\mathrm{P}_{\text {rrnAPCL1 }}$ promoter, matching the in vivo promoter activity (see Fig. 1b).

\section{Regulation by initiating NTP}

Nucleotides serve as important effectors in positive regulation of the rrn promoters. The initiating nucleotide stabilizes the intrinsically short-lived $\mathrm{RP}_{\mathrm{O}}$ by pairing with the template strand (Barker \& Gourse, 2001). The $\mathrm{RP}_{\mathrm{O}}$ formation assays were carried out in the presence of initiating nucleotide GTP at $\mathrm{P}_{r r n A P C L 1}, \mathrm{P}_{r r n B}$ and $\mathrm{P}_{g y r}$. Initially, the effects of different combinations of NTPs $(+1 ;+1$ and $+2 ;+1,+2$ and +3 ; and all four NTPs $)$ on $\mathrm{RP}_{\mathrm{O}}$ formation were tested (Supplementary Fig. S5). The results indicate that the presence of +1 NTP is sufficient to activate $\mathrm{RP}_{\mathrm{O}}$ formation at $\mathrm{P}_{r r n B}$ and to a lesser extent at $\mathrm{P}_{r r n A P C L 1}$ (Fig. 6a). To assess the regulation of $r r n$ promoters by other small molecule effectors, the role of pppGpp in $\mathrm{RP}_{\mathrm{O}}$ stability was tested. The open complex at $\mathrm{P}_{r r n B}$ was destabilized in the presence of pppGpp, whereas pppGpp had no significant effect on $\mathrm{P}_{\text {rrnAPCL1 }}$ and $\mathrm{P}_{g y r}$ (Fig. 6b). As expected, in vitro transcription assays revealed that the inhibition of $\mathrm{P}_{r r n B}$ promoter by pppGpp had no significant effect on $\mathrm{P}_{\text {rrnAPCL1 }}$ and $\mathrm{P}_{g y r}$ (data not shown).

The effect of initiating NTP on open complex formation was tested further by determining the fraction of $\mathrm{RP}_{\mathrm{C}}$ converted into $\mathrm{RP}_{\mathrm{O}}$ in presence of iGTP. The extent of $\mathrm{RP}_{\mathrm{O}}$ formation is lower at $\mathrm{P}_{r r n B}$ in the absence of iGTP (Fig. 6c). However, in the presence of the iGTP, $\mathrm{RP}_{\mathrm{O}}$ formation at $\mathrm{P}_{r r n B}$ increased by nearly fivefold (Fig. 6d). The complex formation was also stimulated at $\mathrm{P}_{\text {rrnAPCL1 }}$ by $\sim 1.5$-fold (Fig. 6c and d). The NTPs stimulate $\mathrm{RP}_{\mathrm{O}}$ formation by increasing the stability of the complex, thus reducing the $k_{\text {off }}$ and enhancing the half-life (Supplementary Fig. S6). Several-fold stimulation of $\mathrm{RP}_{\mathrm{O}}$ formation by iGTP at the $\mathrm{P}_{r r n B}$ promoter also seems to contribute to its overall high promoter strength. As expected, iGTP did not stabilize $\mathrm{RP}_{\mathrm{O}}$ at the $\mathrm{P}_{g y r}$ promoter (Fig. $6 \mathrm{c}$ and $\mathrm{d}$ and Supplementary Fig. S6). Once a ternary complex is formed with the synthesis of the first phosphodiester bond, RNAP could form a stable initiation complex at all three promoters (Supplementary Fig. S7). 

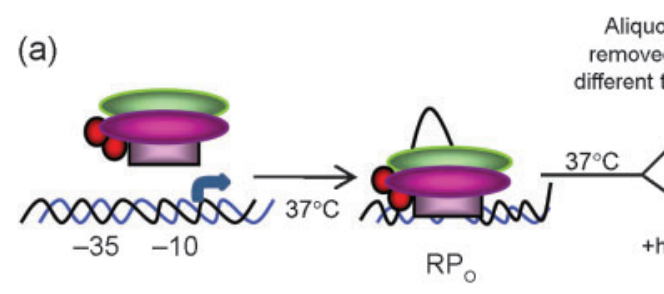

(b)

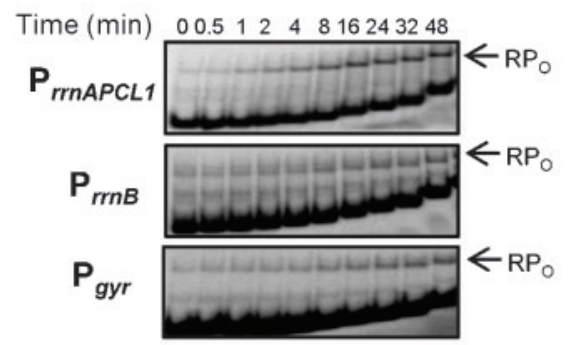

(d)
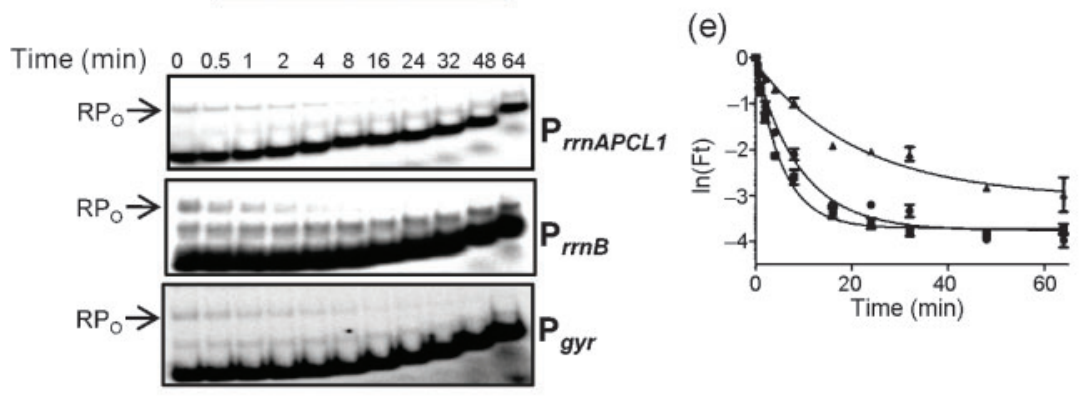

(f)
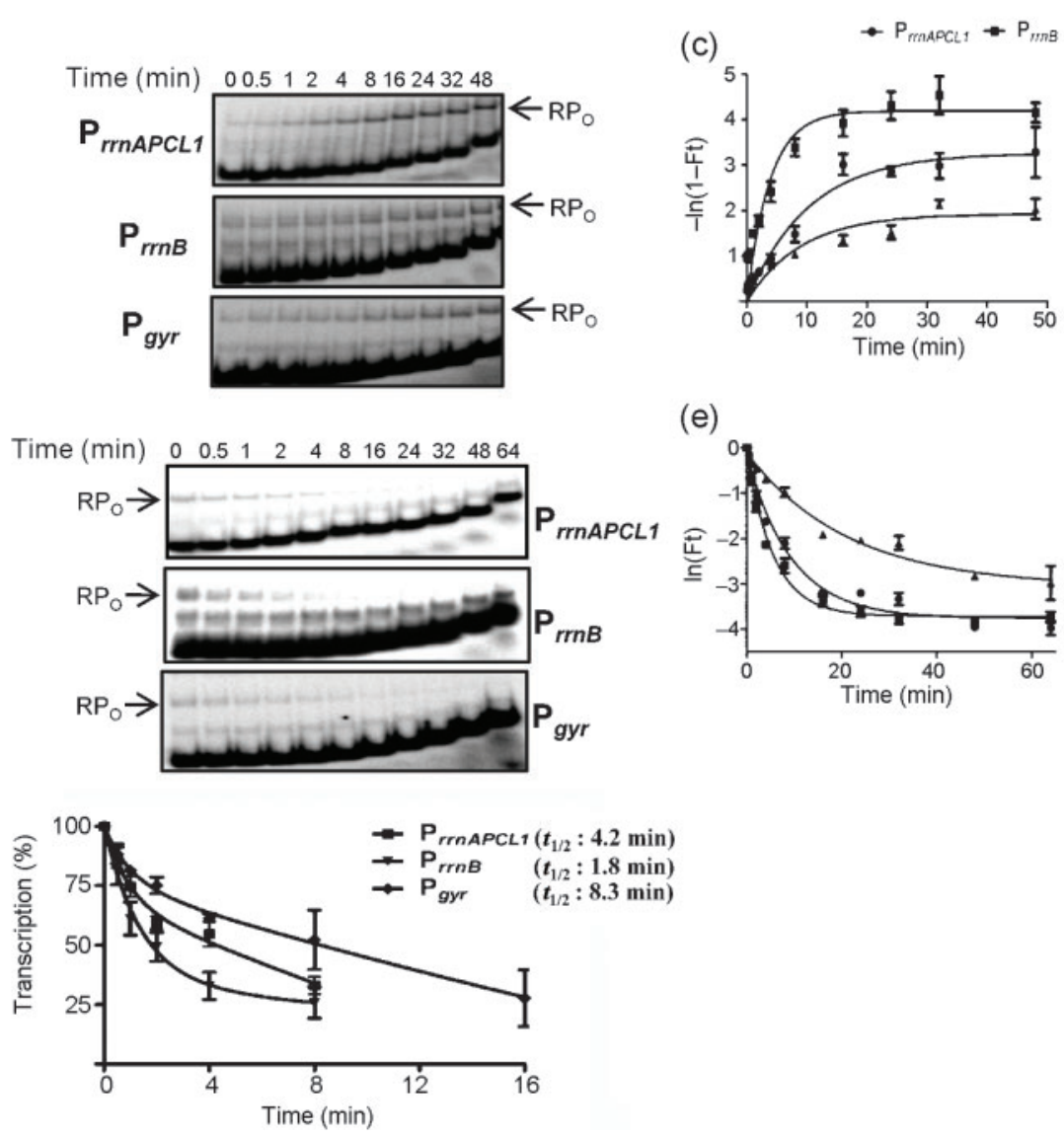

(e)

Fig. 4. Kinetics of $\mathrm{RP}_{\mathrm{O}}$ formation and decay. (a) Representation of the experimental procedure. (b) The formation of complexes between RNAP and the promoters was analysed under pseudo-first-order conditions by monitoring the formation of heparinresistant RP . RNAP $(100 \mathrm{nM})$ and promoter DNA $(1 \mathrm{nM})$ were incubated at $37{ }^{\circ} \mathrm{C}$ and aliquots were removed at various time intervals (0.5-48 min). The samples were challenged with heparin and the extent of $\mathrm{RP}_{\mathrm{O}}$ was measured after separating the complexes by using native PAGE. (c) The data were fitted into a pseudo-first-order kinetic equation. (d) The decay of specific complexes formed between RNAP and promoters in the presence of a competitor (heparin) was monitored by quantification of the heparin-resistant complex $\mathrm{RP}_{\mathrm{O}}$. Complex dissociation was monitored from 0 to 64 min by measuring the fraction of $\mathrm{RP}_{\mathrm{O}}$ remaining after the addition of heparin. (e) The exponential fits of the data were plotted to measure dissociation rate constant, $k_{\text {off, }}$ and the half-life of the decay. (f) Open complex decay by in vitro transcription. The stability of $\mathrm{RP}_{\mathrm{O}}$ was analysed by an in vitro transcription assay using linear DNA templates, which generates run-off transcripts. $\mathrm{RP}_{\mathrm{O}}$ was formed and then challenged with heparin. Aliquots were removed at different time intervals and transcription was initiated by the addition of NTP mix. The per cent transcription was plotted to determine the half-life of $\mathrm{RP}_{\mathrm{O}}$. Data shown are means $\pm \mathrm{SD}$ based on three independent experiments.

\section{DISCUSSION}

After a promoter search, RNAP initiates a complex series of sequential interactions at the promoters culminating in polymerase escape and transcription elongation. The complex functional pathway intrinsic to a given promoter is subjected to different rate-limiting substeps and the promoter strength is the end result of an optimization process involving many parameters. Thus, for each promoter, kinetic properties of the multi-step transcription 
(a)

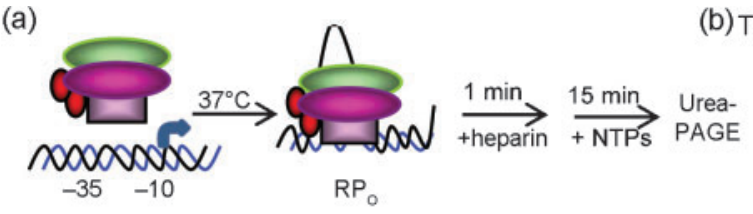

(c)

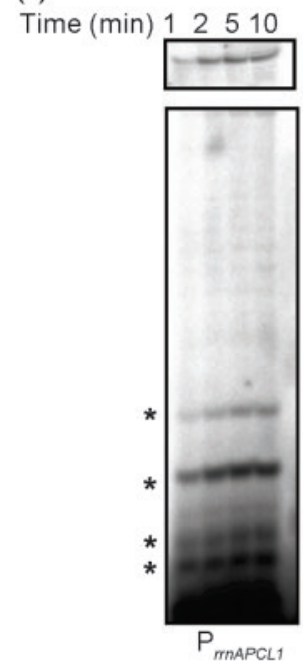

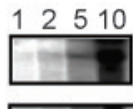

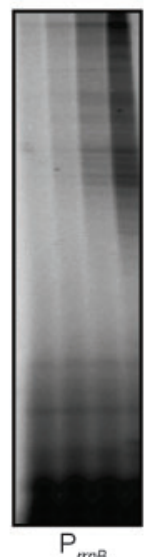

12510

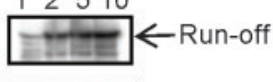

(b) Time (min) $1 \quad 2 \quad 4 \quad 8 \quad 16 \quad 32$

$P$

MAPCL1)

$P_{m}$

$P_{g r}$
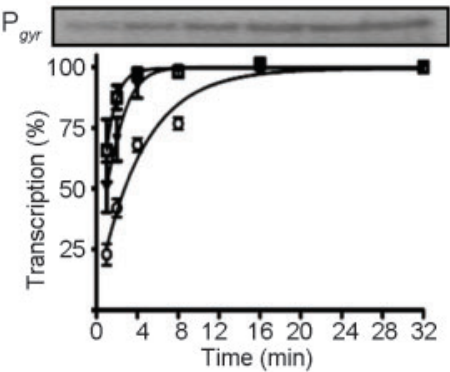

(d)

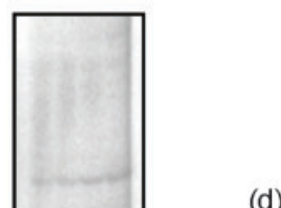

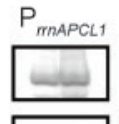
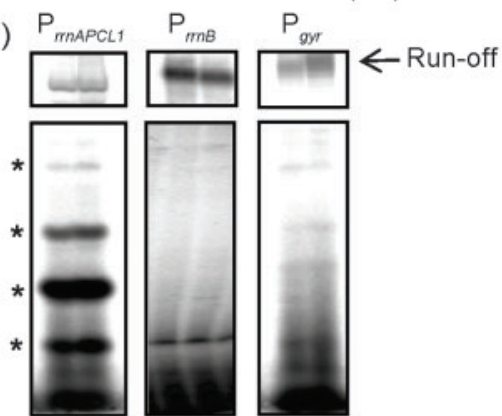

Fig. 5. Promoter clearance efficiency and abortive transcription. (a) Representation of the experimental procedure. (b) Promoter clearance assay. Open complexes were challenged with heparin, and then transcriptions were initiated by the addition of NTP. PC $90 \%$ is shown on the graph. (c) Abortive versus productive transcription. Promoter clearance assays were performed, with aliquots removed at different time intervals (1, 2, 5 and $10 \mathrm{~min}$ ). The transcripts were separated by using $22 \%$ urea-PAGE. Run-off transcripts are shown in separate boxes. The profiles of abortive transcripts at the three promoters are presented in the lower panel; prominent products are marked with asterisks. (d) Multiple round transcriptions from three promoters. Run-off transcripts are shown in the upper panels and abortive products are marked by asterisks.

initiation pathway are distinct and the rate-limiting steps may vary. In this first detailed analysis of mycobacterial promoter-polymerase interactions, we show that the three promoters studied possess different characteristics in spite of being housekeeping promoters with similar architecture. From the data presented, it is evident that each one of the promoters has its own characteristic interaction pattern with the RNAP.

Unlike M. tuberculosis and other slow-growing mycobacteria, which encode a single rRNA operon, M. smegmatis and other fast-growing mycobacteria have two rrn operons, rrnA and rrnB (Menendez et al., 2002; Sander et al., 1996; Stadthagen-Gomez et al., 2008). In the rrnA operon, $\mathrm{P}_{\text {rrnAPCL1 }}$ is conserved across all mycobacteria and contributes about $5 \%$ of rRNA transcripts in exponentially growing $M$. smegmatis cells. The expression levels of this promoter remain unaltered under nutrient starvation conditions (Gonzalez-y-Merchand et al., 1998). The other promoter present in the $r r n A$ operon $\left(\mathrm{P}_{r r n A P 2}\right)$ contributes predominantly to rRNA synthesis during exponential growth phase. This promoter closely resembles $\mathrm{P}_{r r n B}$ used in this study in its architecture, expression pattern and the degree of rRNA synthesis (Gonzalez-y-Merchand et al.,
1997, 1998). M. smegmatis $\mathrm{P}_{r r n B}$, which drives the transcription of the $r r n B$ operon, contributes to more than $40 \%$ of the total rRNA in exponential phase (Gonzalez-yMerchand et al., 1998).

Here, we provide mechanistic insights into the substeps of transcription initiation at two of the rrn promoters $\left(\mathrm{P}_{\text {rrnAPCL1 }}\right.$ and $\left.\mathrm{P}_{r r n B}\right)$, indicating their key regulatory features. In spite of having sequence similarity at the -35 and -10 regions, these two promoters contribute to the total rRNA synthesis to vastly different extents. In accordance with its known characteristics, $\mathrm{RP}_{\mathrm{C}}$ formation (the first identifiable complex during the initiation pathway) was most prominent at $\mathrm{P}_{r r n A P C L 1}$. Furthermore, the isomerization of closed complex to open complex was very efficient at this promoter (Table 2). The extent of isomerization of $\mathrm{RP}_{\mathrm{C}}$ to $\mathrm{RP}_{\mathrm{O}}$ suggested that $\mathrm{P}_{r r n A P C L 1}$ is potentially a strong promoter. However, in vivo activity of this promoter at the exponential phase was relatively low. This study provides an explanation for this observation. Since the promoter escape was compromised due to the synthesis of abortive transcription products, the initial strength of $\mathrm{RP}_{\mathrm{O}}$ formation was not reflected in the final productive transcription at this promoter. On the other 
(a)

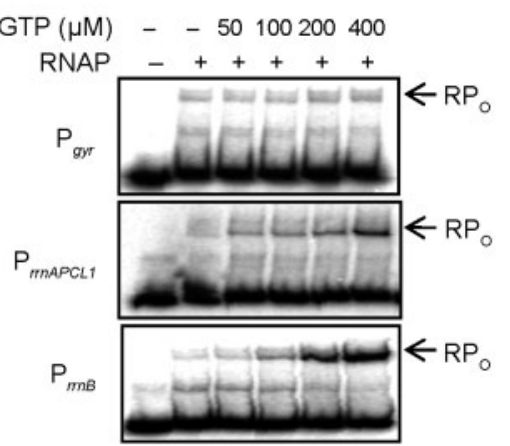

(c)

Complex - $123-123-123$ RNAP -+++-+++-+++

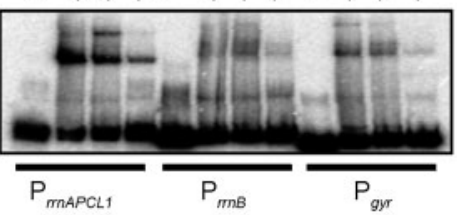

(d)

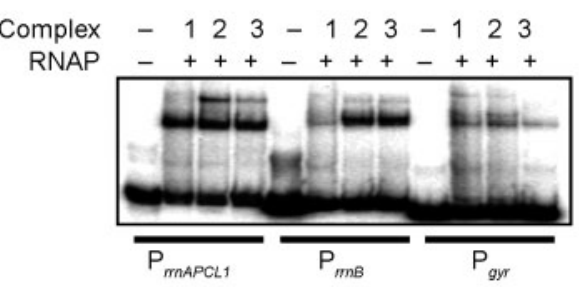

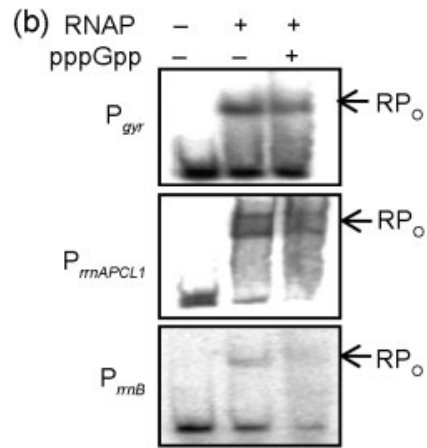
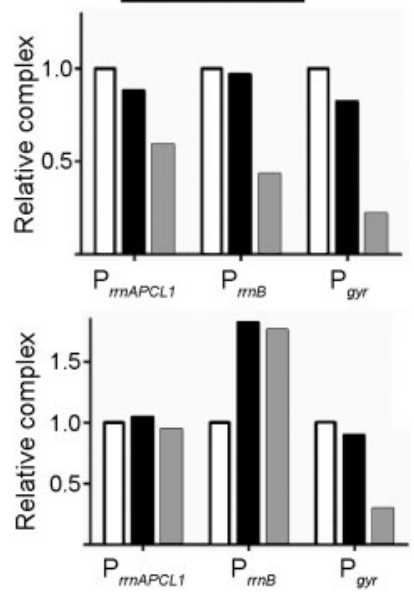

Fig. 6. Effect of iNTP binding on $\mathrm{RP}_{\mathrm{O}}$. (a) Open complex formation assays were performed as described in Methods. The fraction of productive RNAP-promoter complex formed in the absence and presence of initiating NTP was measured. (b) The inhibitory effect of pppGpp on $\mathrm{RP}_{\mathrm{O}}$. Open complexes were formed on the promoter following incubation with $100 \mu \mathrm{M}$ pppGpp and the reactions were resolved by an EMSA. EMSAs were carried out in the presence and absence of $100 \mu \mathrm{M}$ GTP. (c, d) The samples for the closed complex (open bars; 1 ), $37{ }^{\circ} \mathrm{C}$ complex (filled bars; 2) and heparin-resistant complex (shaded bars; 3 ) were taken from the same assay mix and separated on the gel as described in Methods. Assays were carried out in the absence (c) and presence (d) of iNTP. The values on the graph were normalized to the amount of closed complex formed in each assay. hand, $\mathrm{P}_{r r n B}$ was found to be the strongest among all three promoters studied in vivo and is possibly one of the strongest promoters in the exponentially growing mycobacterial cells. The strength of this promoter was mediated at the later steps of transcription initiation, since the equilibrium binding affinity for closed and open complex formation was moderate in the absence of any other factors (Table 2). The faster promoter clearance facilitated the complex to proceed towards elongation rapidly. The $\mathrm{RP}_{\mathrm{O}}$ formation at this promoter was stimulated by the binding of initiating nucleotide iGTP. The activation of the $\mathrm{P}_{r r n B}$ promoter in the presence of iGTP provides another explanation as to why this promoter is one of the strongest in the exponential growth phase, in spite of poor initial RNAP-promoter complex formation. $\mathrm{P}_{r r n B}$ is possibly regulated by growth-rate-dependent transcriptional control. The promoter activity is highest during exponential growth phase due to the presence of optimum concentrations of NTPs. In nutrient starvation conditions, NTP levels would go down, leading to a decrease in $\mathrm{P}_{r r n B}$ promoter activity (Gonzalez-y-Merchand et al., 1998; Verma et al., 1999). pppGpp is known to exert stringent control of transcription by decreasing the stability of unstable open complexes at $r r n$ promoters (Haugen et al., 2008). Accordingly, we observed inhibitory effects of the alarmone pppGpp at this promoter. In contrast, $\mathrm{P}_{\text {rrnAPCL1 }}$ is not inhibited to a significant extent by pppGpp and is also not stimulated by iGTP to the same extent as $\mathrm{P}_{r r n B}$. The transcription at this promoter is further compromised at the promoter clearance step by high rates of abortive transcription, possibly contributed by both its promoter recognition region and initial transcribed sequence. $\mathrm{P}_{\text {rrnAPCL1 }}$ may be responsible for carrying out the basal level of rRNA transcription activity required in stationary phase and in nutrient-starved conditions, as the total amount of RNA synthesized from this promoter remains unaltered. These conclusions were based on the primer extension analysis of RNA isolated from $M$. smegmatis cultures grown in complete medium or in carbon-limiting medium (Gonzalez-y-Merchand et al., 1998). During balanced growth in the complete medium, $\mathrm{P}_{r r n B}$ was the major contributor towards pre-rRNA synthesis, whereas in stationary phase, activity of this promoter was reduced and $\mathrm{P}_{\text {rrnAPCL1 }}$ served as one of the major sources of rRNA transcripts. Detailed studies carried out with $\mathrm{rrn}$ promoter regulation in $E$. coli provide parallels to the results obtained with two mycobacterial promoters. In all the seven E. coli operons, the first of the two promoters $\left(\mathrm{P}_{r r n A 1}, \mathrm{P}_{r r n B 1}\right.$ etc.) contributes predominantly during exponential phase and is upregulated to a high level in response to growth-ratedependent regulation by iNTP, whereas $\mathrm{P}_{r r n P 2}$ appears to have a major role during stationary phase (Murray \& Gourse, 2004). The open complex lifetime of $\mathrm{P}_{r r n P 2}$ was found to be more than that for $\mathrm{P}_{r r n P 1}$, and it is not significantly regulated by iNTP (Murray \& Gourse, 2004). M. smegmatis $r r n B$ promoter is very much like the E. coli $r r n P 1$ promoter in overall properties, thus revealing common features shared by the bacteria for stable RNA transcription. Promoters driving transcription for the genes encoding DNA gyrase are, in general, regulated by 
DNA topology to maintain the overall negative supercoiled nature of the genome. Earlier studies showed that $\mathrm{P}_{g y r}$ is a strong promoter in M. smegmatis during exponential growth (Unniraman \& Nagaraja, 1999). From the present study, it is evident that $\mathrm{P}_{g y r}$ has moderately strong equilibrium and kinetic parameters (in between the two $r r n$ promoters studied) and promoter clearance is fast, with minimal abortive transcripts (Table 2). $\mathrm{P}_{g y r}$ had the slowest rate of $\mathrm{RP}_{\mathrm{O}}$ decay but also had fast promoter escape in the presence of NTPs. Thus, the rate-limiting step at this promoter appears to be the initial binding of RNAP to the promoter, which might depend on local DNA conformations separate from the sequence.

In conclusion, the analysis of the transcription initiation pathway of $\sigma^{\mathrm{A}}$-dependent promoters of $M$. smegmatis provides the first insights into the general mechanism of promoter-RNAP interactions in mycobacteria. The steadystate kinetics are influenced by the nature of individual promoters and their interactions with RNAP. From studies in E. coli and other organisms, it is apparent that ratelimiting steps are targeted by regulatory proteins. Thus, it is conceivable that some of the cellular regulators in mycobacteria would target rate-limiting steps at these promoters. Finally, various assays to study the early steps of transcription, described here using mycobacterial RNAP and promoters, would be useful in elucidating the mechanism of action of various transcription activators and repressors of this important genus.

\section{ACKNOWLEDGEMENTS}

We acknowledge Professor Dipankar Chatterji of the Molecular Biophysics Unit, IISc, for pppGpp. The Phosphorimager facility of IISc supported by the Department of Biotechnology, Government of India, is acknowledged. A.C. and P.T. are recipients of Senior Research and Junior Research Fellowships from the Council of Scientific and Industrial Research and University Grants Commission, Government of India, respectively. V. N. is a recipient of a J. C. Bose Fellowship from Department of Science and Technology, Government of India. The work was supported by a Center for Excellence in Tuberculosis Research grant from the Department of Biotechnology, Government of India.

\section{REFERENCES}

Arnvig, K. B., Gopal, B., Papavinasasundaram, K. G., Cox, R. A. \& Colston, M. J. (2005). The mechanism of upstream activation in the $\mathrm{rrnB}$ operon of Mycobacterium smegmatis is different from the Escherichia coli paradigm. Microbiology 151, 467-473.

Barker, M. M. \& Gourse, R. L. (2001). Regulation of rRNA transcription correlates with nucleoside triphosphate sensing. J Bacteriol 183, 6315-6323.

Brosch, R., Pym, A. S., Gordon, S. V. \& Cole, S. T. (2001). The evolution of mycobacterial pathogenicity: clues from comparative genomics. Trends Microbiol 9, 452-458.

Browning, D. F. \& Busby, S. J. (2004). The regulation of bacterial transcription initiation. Nat Rev Microbiol 2, 57-65.
Brunner, M. \& Bujard, H. (1987). Promoter recognition and promoter strength in the Escherichia coli system. EMBO J 6, 3139-3144.

Buc, H. \& McClure, W. R. (1985). Kinetics of open complex formation between Escherichia coli RNA polymerase and the lac UV5 promoter. Evidence for a sequential mechanism involving three steps. Biochemistry 24, 2712-2723.

Burns, H. D., Belyaeva, T. A., Busby, S. J. \& Minchin, S. D. (1996). Temperature-dependence of open-complex formation at two Escherichia coli promoters with extended -10 sequences. Biochem J 317, 305-311.

Chakraborty, A. \& Nagaraja, V. (2006). Dual role for transactivator protein $\mathrm{C}$ in activation of mom promoter of bacteriophage Mu. J Biol Chem 281, 8511-8517.

China, A. \& Nagaraja, V. (2010). Purification of RNA polymerase from mycobacteria for optimized promoter-polymerase interactions. Protein Expr Purif 69, 235-242.

Cole, S. T., Brosch, R., Parkhill, J., Garnier, T., Churcher, C., Harris, D., Gordon, S. V., Eiglmeier, K., Gas, S. \& other authors (1998). Deciphering the biology of Mycobacterium tuberculosis from the complete genome sequence. Nature 393, 537-544.

Gomez, M. \& Smith, I. (2000). Determinants of mycobacterial gene expression. In Molecular Genetics of Mycobacteria. Edited by G. F. Hatfull \& W. R. Jacobs, Jr. Washington, DC: American Society for Microbiology.

Gomez, M., Doukhan, L., Nair, G. \& Smith, I. (1998). sigA is an essential gene in Mycobacterium smegmatis. Mol Microbiol 29, 617-628.

Gonzalez-y-Merchand, J. A., Garcia, M. J., Gonzalez-Rico, S., Colston, M. J. \& Cox, R. A. (1997). Strategies used by pathogenic and nonpathogenic mycobacteria to synthesize rRNA. J Bacteriol 179, 6949-6958.

Gonzalez-y-Merchand, J. A., Colston, M. J. \& Cox, R. A. (1998). Roles of multiple promoters in transcription of ribosomal DNA: effects of growth conditions on precursor rRNA synthesis in mycobacteria. J Bacteriol 180, 5756-5761.

Haugen, S. P., Ross, W. \& Gourse, R. L. (2008). Advances in bacterial promoter recognition and its control by factors that do not bind DNA. Nat Rev Microbiol 6, 507-519.

Helmann, J. D. (2009). RNA polymerase: a nexus of gene regulation. Methods 47, 1-5.

Helmann, J. D. \& deHaseth, P. L. (1999). Protein-nucleic acid interactions during open complex formation investigated by systematic alteration of the protein and DNA binding partners. Biochemistry 38, 5959-5967.

Hsu, L. M. (2009). Monitoring abortive initiation. Methods 47, 25-36.

Jain, S., Kaushal, D., DasGupta, S. K. \& Tyagi, A. K. (1997). Construction of shuttle vectors for genetic manipulation and molecular analysis of mycobacteria. Gene 190, 37-44.

Ji, Y. E., Colston, M. J. \& Cox, R. A. (1994). The ribosomal RNA ( $r r n)$ operons of fast-growing mycobacteria: primary and secondary structures and their relation to $\mathrm{rrn}$ operons of pathogenic slowgrowers. Microbiology 140, 2829-2840.

Jia, Y. \& Patel, S. S. (1997). Kinetic mechanism of transcription initiation by bacteriophage T7 RNA polymerase. Biochemistry 36, 4223-4232.

Juang, Y.-L. \& Helmann, J. D. (1995). Pathway of promoter melting by Bacillus subtilis RNA polymerase at a stable RNA promoter: effects of temperature, delta protein, and sigma factor mutations. Biochemistry 34, 8465-8473.

Lisser, S. \& Margalit, H. (1993). Compilation of E. coli mRNA promoter sequences. Nucleic Acids Res 21, 1507-1516.

Lutz, R., Lozinski, T., Ellinger, T. \& Bujard, H. (2001). Dissecting the functional program of Escherichia coli promoters: the combined mode 
of action of Lac repressor and AraC activator. Nucleic Acids Res 29, 3873-3881.

Manganelli, R., Dubnau, E., Tyagi, S., Kramer, F. R. \& Smith, I. (1999). Differential expression of 10 sigma factor genes in Mycobacterium tuberculosis. Mol Microbiol 31, 715-724.

McClure, W. R. (1985). Mechanism and control of transcription initiation in prokaryotes. Annu Rev Biochem 54, 171-204.

Menendez, M. C., Garcia, M. J., Navarro, M. C., Gonzalez-yMerchand, J. A., Rivera-Gutierrez, S., Garcia-Sanchez, L. \& Cox, R. A. (2002). Characterization of an rRNA operon $(\mathrm{rrnB})$ of Mycobacterium fortuitum and other mycobacterial species: implications for the classification of mycobacteria. J Bacteriol 184, 10781088.

Miller, J. H. (1992). A Short Course in Bacterial Genetics: a Laboratory Manual and Handbook for Escherichia Coli and Related Bacteria, p. 71. Cold Spring Harbor, NY: Cold Spring Harbor Laboratory Press.

Mukherjee, R. \& Chatterji, D. (2008). Stationary phase induced alterations in mycobacterial RNA polymerase assembly: a cue to its phenotypic resistance towards rifampicin. Biochem Biophys Res Commun 369, 899-904.

Murray, H. D. \& Gourse, R. L. (2004). Unique roles of the $r r n$ P2 rRNA promoters in Escherichia coli. Mol Microbiol 52, 1375-1387.

Nudler, E. (2009). RNA polymerase active center: the molecular engine of transcription. Annu Rev Biochem 78, 335-361.

Rodrigue, S., Provvedi, R., Jacques, P. E., Gaudreau, L. \& Manganelli, R. (2006). The sigma factors of Mycobacterium tuberculosis. FEMS Microbiol Rev 30, 926-941.

Sander, P., Prammananan, T. \& Bottger, E. C. (1996). Introducing mutations into a chromosomal rRNA gene using a genetically modified eubacterial host with a single rRNA operon. Mol Microbiol 22, 841-848.

Schneider, D. A., Murray, H. D. \& Gourse, R. L. (2003). Measuring control of transcription initiation by changing concentrations of nucleotides and their derivatives. Methods Enzymol 370, 606-617.

Schroeder, L. A., Choi, A. J. \& DeHaseth, P. L. (2007). The -11 A of promoter DNA and two conserved amino acids in the melting region of $\sigma 70$ both directly affect the rate limiting step in formation of the stable RNA polymerase-promoter complex, but they do not necessarily interact. Nucleic Acids Res 35, 4141-4153.
Smith, I., Bishai, W. R. \& Nagaraja, V. (2005). Control of mycobacterial transcription. In Tuberculosis and the Tubercle Bacillus, pp. 219-231. Edited by S. T. Cole, K. D. Eisenach, D. N. McMurray \& W. R. Jacobs, Jr. Washington, DC: American Society for Microbiology.

Snapper, S. B., Melton, R. E., Mustafa, S., Kieser, T. \& Jacobs, W. R., Jr (1990). Isolation and characterization of efficient plasmid transformation mutants of Mycobacterium smegmatis. Mol Microbiol 4, 1911-1919.

Stadthagen-Gomez, G., Helguera-Repetto, A. C., Cerna-Cortes, J. F., Goldstein, R. A., Cox, R. A. \& Gonzalez-y-Merchand, J. A. (2008). The organization of two rRNA ( $r r n)$ operons of the slowgrowing pathogen Mycobacterium celatum provides key insights into mycobacterial evolution. FEMS Microbiol Lett 280, 102-112.

Straney, S. B. \& Crothers, D. M. (1987). Kinetics of the stages of transcription initiation at the Escherichia coli lac UV5 promoter. Biochemistry 26, 5063-5070.

Triccas, J. A., Parish, T., Britton, W. J. \& Gicquel, B. (1998). An inducible expression system permitting the efficient purification of a recombinant antigen from Mycobacterium smegmatis. FEMS Microbiol Lett 167, 151-156.

Tsujikawa, L., Tsodikov, O. V. \& deHaseth, P. L. (2002). Interaction of RNA polymerase with forked DNA: evidence for two kinetically significant intermediates on the pathway to the final complex. Proc Natl Acad Sci U S A 99, 3493-3498.

Unniraman, S. \& Nagaraja, V. (1999). Regulation of DNA gyrase operon in Mycobacterium smegmatis: a distinct mechanism of relaxation stimulated transcription. Genes Cells 4, 697-706.

Unniraman, S., Chatterji, M. \& Nagaraja, V. (2002). DNA gyrase genes in Mycobacterium tuberculosis: a single operon driven by multiple promoters. J Bacteriol 184, 5449-5456.

Verma, A., Sampla, A. K. \& Tyagi, J. S. (1999). Mycobacterium tuberculosis rrn promoters: differential usage and growth ratedependent control. J Bacteriol 181, 4326-4333.

Waagmeester, A., Thompson, J. \& Reyrat, J. M. (2005). Identifying sigma factors in Mycobacterium smegmatis by comparative genomic analysis. Trends Microbiol 13, 505-509.

Edited by: J.-H. Roe 